RERTATE DIE MLALES

Campinas-SP, v.41, n.2, pp. 502-522, jul./dez. 2021

\title{
O RELATO (ÉTICO) DE UM TRADUTOR DE MAURICE BLANCHOT
}

\author{
THE (ETHICAL) REPORT OF A \\ MAURice BLANCHOT'S Translator
}

\author{
Davi Andrade Pimentel ${ }^{1}$
}

Resumo: Neste artigo, com base em minha experiência de tradutor do escritor francês Maurice Blanchot, proponho algumas reflexões sobre a tradução enquanto ato ético, entendendo por ato ético o respeito pela diferença da língua do outro estrangeiro, o que significa não aclimatá-la à língua do tradutor, mas sim deixá-la abrir novos espaços sintáticos e semânticos em minha própria língua. Nesse percurso, além da análise da tradução de fragmentos escolhidos da narrativa L'attente l'oubli, de Blanchot, pretendo dialogar com três ideias essenciais, a meu ver, ao ato tradutório: a primeira, a ideia de Jacques Lacan sobre a letra como materialidade do significante; a segunda, a ideia de Antoine Berman sobre a ética na tradução; e, a terceira, a ideia do próprio Blanchot sobre a tradução enquanto diferença.

Palavras-chave: L'attente l'oubli; tradução ética; outro estrangeiro.

\begin{abstract}
On this article, based on my experience as a translator of the French writer Maurice Blanchot, I propose some reflections on translation as an ethical act, understanding ethical act as the respect to the difference of the foreign language of the other, which means not adjusting it to the translator's language, but let it open new syntactic and semantic spaces on my own language. Through this journey, besides the analysis of the chosen fragments of Blanchot's narrative L'attente l'oubli, I intend to dialogue with three ideas that, for me, are essential to the translation act: the first, Jacques Lacan's idea about the letter as the materiality of the signifier; the second, the idea of Antoine Berman on translation's ethic; and, the third, Blanchot's idea about translation as a different thing. Keywords: L'attente l'oubli; Ethical Translation; The Foreign Other.
\end{abstract}

${ }^{1}$ Pós-doutorando em Tradução do Programa de Pós-graduação em Ciência da Literatura da Universidade Federal do Rio de Janeiro. Bolsista Faperj: <davi_a_pimentel@yahoo.com.br>. 


\begin{abstract}
"Savons-nous tout ce que nous devons aux traducteurs et, plus encore, à la traduction? Nous le savons mal. Et même si nous avons de la gratitude pour les hommes qui entrent vaillamment dans cette énigme qu'est la tâche de traduire, si nous les saluons de loin comme les maîtres cachés de notre culture, liés à eux et docilement soumis à leur zèle, notre reconnaissance reste silencieuse, un peu dédaigneuse, d'ailleurs par humilité, car nous ne sommes pas en mesure de leur être reconnaissants."

(Maurice Blanchot, "Traduire”)
\end{abstract}

\title{
CONSIDERAÇÕES INICIAIS
}

"Repudio esse certificado: não sou um poeta, mas um poema.

E que se escreve, apesar de ter jeito de ser sujeito." (Jacques Lacan. Prefácio à edição inglesa do Seminário 11)

Neste artigo, não pretendo dar voz a um relato sobre tradução, por assim dizer, subjetivo demais ou em excesso subjetivo, que certamente suplantaria a alteridade que se deseja inalienável do outro estrangeiro, no caso, a estrangeiridade do escritor francês Maurice Blanchot: "Não é a liberdade que caracteriza o outro inicialmente, da qual em seguida deduzir-se-á a alteridade; é a alteridade que o outro traz como essência" (LEVINAS, 2011, p. 8o). ${ }^{3}$ O outro enquanto não sucedâneo do eu, enquanto um não eu-mesmo, princípio defendido por Emmanuel Levinas em seu livro Le temps et l'autre [O tempo e o outro], é o que caracteriza, a meu ver, o olhar ético sobre o trabalho tradutório, ou seja, compreender que entre mim e o outro, seja ele estrangeiro ou não, há uma distância que precisa ser respeitada para que nem eu nem o outro sejamos submetidos a uma força aniquiladora.

Essa distância, que já se insere entre mim e o outro, ganha uma complexidade maior na narrativa L'attente l'oubli [A espera o esquecimento], de Blanchot, uma vez que ela será amplificada pela palavra

\footnotetext{
2 "Sabemos tudo o que devemos aos tradutores e, mais ainda, à tradução? Mal sabemos. E mesmo se temos gratidão pelos homens que entram corajosamente nesse enigma que é a tarefa de traduzir, se os saudamos de longe como os mestres ocultos de nossa cultura, ligados a eles e facilmente submetidos a seu zelo, nosso reconhecimento permanece silencioso, um pouco desdenhoso, aliás por humildade, pois não estamos à altura de lhes sermos gratos." (BLANCHOT, 1971, p. 69) Todas as traduções dos textos em francês citados neste artigo são de minha autoria.

3 "Ce n'est pas la liberté qui caractérise l'autre initialement, dont ensuite se déduira l'altérité; c'est l'altérité que l’autre porte comme essence.”
} 
ficcional blanchotiana, produzindo, por meio das ramificações discursivas dessa narrativa, distanciamentos expressivos entre o seu significante e os seus possíveis significados. Disso resulta que a distância, ou o chamado do distanciamento, passa a ser um dos modos de designação da narrativa blanchotiana que, por sua vez, precisa ser buscado e mantido por seu tradutor ou futuro tradutor: "a tradução deve, ao invés de procurar assemelhar-se ao sentido do original, conformar-se amorosamente, e nos mínimos detalhes, em sua própria língua, ao modo de designar do original" (BENJAMIN, 2013, p. 115). Porém, Blanchot torna a complexidade da distância ainda mais problemática quando a recobre com o véu dissimulado de um chamado de aproximação que se estabelece entre um ele e um ela, jamais entre o ele e o ela, pois ambos são, antes de tudo, vozes neutras - indefinidas.

Nas 122 páginas de $A$ espera o esquecimento, o chamado produzido por um ela, possivelmente a voz narrativa ou a voz da literatura, a um ele, um provável candidato a escritor - "Fais en sorte que je puisse te parler" ["Aja de modo que eu possa falar com você"], que traduzo buscando manter a sua tensão próximo-distante por meio do imperativo do verbo agir, que demarca implicitamente condições para a aproximação -,inscreve-se oito vezes ao longo da estrutura textual, como oito nexos distendidos por todo o texto que, contrários à sua função, des-conectam tanto os fragmentos que constituem a obra $A$ espera o esquecimento quanto a esperada espera que jamais deixa de ser a espera por/de algo e pelo/do outro. Um chamado de aproximação que oculta, na verdade, um chamado do distanciamento, pois aquele que o ouve, o ele, está im-possibilitado de saber se escreve de fato ou se é de fato um escritor - o esquecimento originado por ela o distancia de qualquer certeza:

No original:

* Fais en sorte que je puisse te parler.

"Que dois-je dire?" - "Que voulez-vous dire?" - “Cela qui, si je le disais, détruirait cette volonté de dire" (BLANCHOT, 1962, p. 19).

Tradução:

* Aja de modo que eu possa falar com você.

"O que devo dizer?" - "O que você quer dizer?" - "Isso que, se eu o dissesse, destruiria essa vontade de dizer".

Estruturada a partir de fragmentos, a narrativa de $A$ espera o esquecimento performa, de modo fragmentário e totalizante, em sua des-escrita, aquilo que Blanchot (2010b, p. 150) nomeou em "A voz narrativa 
(o 'ele', o neutro)", tomo III de A conversa infinita, de voz narrativa: "A voz narrativa carrega o neutro. Carrega-o na medida em que: 1) falar no neutro é falar à distância, reservando essa distância, sem mediação nem comunidade". Embora haja o desejo de aproximação, a voz neutra encenada em $A$ espera o esquecimento convoca, a bem da verdade, o distanciamento derivado do esquecimento que, por sua vez, é também esperado. Nesse jogo de escrita blanchotiana entre a espera-esquecimento e a aproximação-distanciamento, o original exige de seu tradutor não apenas uma tomada de posição ética, uma distância não aniquiladora, como também uma manutenção desse chamamento à distância que se apresenta em Blanchot, tanto em suas narrativas quanto em suas obras teórico-críticas, como um chamamento ao neutro:

No original:

* Attendre, se rendre attentif à ce qui fait de l'attente un acte neutre, enroulé sur soi, serré en cercles dont le plus intérieur et le plus extérieur coïncident, attention distraite en attente et retournée jusqu'à l'inattendu. Attente, attente qui est le refus de rien attendre, calme étendue déroulée par le pas (BLANCHOT, 1962, p. 16).

Tradução:

* Esperar, se deixar atento ao que faz da espera um ato neutro, enrolado sobre si, apertado em círculos dentre os quais o mais interior e o mais exterior coincidem, atenção distraída em espera e voltada até o inesperado. Espera, espera que é a recusa de nada esperar, calma extensão desenrolada pelo passo/não.

Nesse fragmento, o tradutor encontrará uma dificuldade, a tradução da palavra pas, que, em francês, sobretudo no francês de Blanchot, encontra no português duas traduções: pas enquanto advérbio de negação não e pas enquanto substantivo passo. Em francês, apenas o contexto apontará em relação a qual significado/significante a palavra pas está articulada. Em português, num primeiro momento, poderemos dizer o mesmo, ainda que, em Blanchot e em outros escritores, a tradução da palavra pas se torne problemática, pois, como se observa no fragmento acima destacado, o contexto não evidencia o significado de pas, antes o ambiguiza. Ou seja, o fragmento faz convergirem tanto a espera do movimento (o não) quanto o seguir em frente do movimento de espera (o passo). Para a tradução desse fragmento, em respeito à letra blanchotiana, optei por dar ao leitor brasileiro a oportunidade de sentir essa ambiguidade da palavra pas no original, embora essa ambiguidade se torne bastante evidente na tradução [pelo passo/não], enquanto no original ela reste sob a letra, indefinida. 
Por meio dessa in-definição, que dialoga com a in-traduzibilidade, exemplificada neste artigo pela palavra pas, não há meios para crer que o texto traduzido seja o reflexo autêntico do texto original, uma vez que o outro não é um eu mesmo, embora a ideia de tradução, enquanto equivalência - uma palavra da língua de chegada equivalendo a uma palavra da língua de partida -, ainda hoje encontre adeptos no campo da tradução. Paul Ricœur, em "Desafio e felicidade da tradução”, do livro Sobre a tradução, alerta-nos que o espectro da in-traduzibilidade que assombra todo início de tradução encontra sua origem na ideia das equivalências de significantes entre duas ou mais línguas distintas:

E a dificuldade é elevada ao máximo com as palavras-chave, as Grundwörter, que o tradutor se impõe, por vezes de modo equivocado, de traduzir palavra por palavra, a mesma palavra recebendo um equivalente fixo na língua de chegada (RICEUR, 2011, pp. 24-5).

Em A tradução e a letra ou O albergue do longínquo, Antoine Berman retoma a problemática da equivalência para desvelar o que há de mais profundo e recalcado nessa prática tradutória: a ideia de supremacia de uma língua em relação a outras línguas e, consequentemente, a ideia de que o outro estrangeiro pode ser facilmente aclimatado à língua de chegada, dando a entender que o outro não teria características tão relevantes que não pudessem ser facilmente remodeladas a partir da língua de chegada, que seria a língua do tradutor. Nesse sentido, o tradutor, muitas vezes, acredita-se conscientemente como o facilitador dos leitores de sua língua, muito embora de modo inconsciente ele esteja praticando uma tradução etnocêntrica: "Pois procurar equivalentes, não significa apenas estabelecer um sentido invariante [...]. Significa recusar introduzir na língua para a qual se traduz a estranheza do provérbio original" (BERMAN, 2007, p. 17). Esse autor, em "Anúncio do percurso", procura enfatizar que "a tradução é tradução-da-letra, do texto enquanto letra” (p. 25). Para logo depois concluir: "Em suas regiões mais profundas, o traduzir está ligado à ética, à poesia e ao pensamento. [...] Mas o ético, o poético, o pensante e o religioso, por sua vez, definem-se em relação ao que chamamos a 'letra'. A letra é seu espaço de jogo" (p. 26). Ou seja, não há tradução que não corresponda em ato ao pensamento sobre tradução. O traduzir e o pensar sobre a tradução são atos em comum, justapostos e intercambiáveis, que operam no próprio ato de tradução de um texto, uma vez que não se trata de traduzir palavra por palavra, mas de buscar traduzir o outro em toda a sua diferença, respeitando a sua estranheza e 
a sua singularidade linguística: "O ato ético consiste em reconhecer e em receber o Outro enquanto Outro" (BERMAN, 2007, p. 68).

A ênfase dada por Berman à letra dialoga com o texto "A instância da letra no inconsciente ou a razão desde Freud", de Jacques Lacan (1998, p. 498), presente em Escritos: "Designamos por letra este suporte material que o discurso concreto toma emprestado da linguagem". Tanto para um quanto para outro, a letra é a materialidade do significante, cuja importância na linguagem supera a do significado, como veremos a seguir. Para Berman, é no respeito à letra estrangeira, e não simplesmente ao seu sentido, que o trabalho tradutório deverá se empenhar para escapar do etnocentrismo e da hipertextualidade, pois está na letra a fenda possível por onde o espaço do outro poderá ser explorado: "Ora, a tradução, com seu objetivo de fidelidade, pertence originariamente à dimensão ética. Ela é, na sua essência, animada pelo desejo de abrir o Estrangeiro enquanto Estrangeiro ao seu próprio espaço de língua" (BERMAN, 2007, p. 69). Já para Lacan (1998, p. 498), a letra estrutura o inconsciente; este, para o psicanalista, é linguagem: "Nosso título deixa claro que, para-além dessa fala, é toda a estrutura da linguagem que a experiência psicanalítica descobre no inconsciente".

Porém, cabe a nós lembrarmos que antes da letra lacaniana e da letra bermaniana está Sigmund Freud. Em "Animismo, magia e onipotência dos pensamentos", de Totem e tabu, ele afirma que: "[h]oje em dia não mais atribuímos imutabilidade e indestrutibilidade aos processos conscientes, e sim aos inconscientes, e consideramos estes os autênticos veículos da atividade psíquica" (FREUD, 2012, p. 148). Se, como destaca o autor, o veículo por excelência das atividades psíquicas é o inconsciente e se, como defende Lacan, o inconsciente é linguagem, logo, o processo tradutório, sendo o trabalho pela letra, está muito mais próximo das atividades do inconsciente do que daquelas do consciente - e essa conclusão pode ser exemplificada via Blanchot.

Analisando a letra de $A$ espera o esquecimento, apreende-se que as vozes narrativas - vozes no plural, porque a voz narrativa se faz dupla, em dupla, entre um ela e um ele - atuam na espera de algo e no seu antecipatório esquecimento, mobilizando o seu inconsciente de escrita. Em outras palavras, aquilo que é dito, apresentado, na narrativa como desejo está revestido de um oculto afastamento, ou melhor, de um desejo de afastamento. E, nesse desejo vazio, em vazies, o diálogo narrativo se desenvolve sem jamais chegar a uma possibilidade de escrita consciente 
de fato, de um desejo real mobilizado pelo consciente da linguagem. Por exemplo, todo desejo de aproximação, “Aja de modo que eu possa falar com você", de A espera o esquecimento tem como oposto o reforço reativo do inconsciente da escrita, no qual o desejo de afastamento está reprimido, ou seja, está sob a letra, estando no inconsciente discursivo da narrativa blanchotiana o reforço que, por outro lado, torna consciente o seu oposto: o desejo de aproximação:

No original:

* Fais en sorte que je puisse te parler. Le désirait-elle vraiment? Était-elle sûre qu'elle ne le regretterait pas? [...] Il sait depuis toujours qu'il n'y a rien là qui ne puisse être exprimé par les mots les plus communs, mais à condition que lui-même appartienne à ce même secret, au lieu de le connaître, et renonce à sa part de lumière en ce monde (BLANCHOT, 1962, p. 21).

Tradução:

* Aja de modo que eu possa falar com você. Ela o desejava mesmo? Ela estava segura de que não o lamentaria? [...] Ele sabe desde sempre que não há nada ali que não possa ser expresso pelas palavras mais comuns, mas com a condição de que ele mesmo pertença a esse mesmo segredo, no lugar de conhecê-lo, e renuncie a sua parte de luz nesse mundo.

Apesar de possível, o segredo guardado pelo ela permanecerá impossível deser expressoenquanto se mantiver na superfíciedoconsciente da escrita. Para que seja possível a expressão do segredo, ser-lhe-á exigido como contrapartida o sacrifício de sua escrita consciente, perdendo assim a sua parcela de luz neste mundo. Em $A$ espera o esquecimento, a voz narrativa para ser ouvida exige daquele que a lê e daquele que se propõe a traduzi-la uma imersão na noite, no segredo, naquilo que se mantém sob a letra, preservado em seu inconsciente de escrita: "Opostos são sempre muito ligados e com frequência formam pares, de maneira que um pensamento é muito fortemente consciente, mas sua contraparte é reprimida e inconsciente" (FREUD, 2016, p. 235).

Em sua teoria do significante, Lacan se apropria de algumas concepções da linguística saussuriana, como, por exemplo, as ideias de significante, de significado e de signo, para logo depois subvertê-las, dando origem à sua teoria - esta que produzirá uma desconstrução, ao nível derridiano, dos conceitos-chave da linguística, especificamente os conceitos de significante e de significado. Para além do trabalho sobre a arbitrariedade do signo linguístico, iniciado por Ferdinand de Saussure, em seu Curso de linguística geral, segundo o qual não há imediaticidade legítima entre significante e significado, entre letra e ser/coisa, Lacan se 
posiciona de modo um tanto mais subversivo ao propor que o significante nada significa de fato ou, por outro lado, pode significar qualquer coisa. De acordo com o psicanalista, o significante, a letra, não tem o seu sentido associado a um ser ou a uma coisa, que por um condicionamento social lhe foi imputado representar, pelo contrário, o sentido do significante dar-se-á na cadeia dos significantes, na qual o seu sentido possível se apresentará a partir das semelhanças e diferenças em relação a outros significantes será exatamente nesse jogo entre significantes que o sentido possível de um significante poderá ser estabelecido em um determinado momento de discurso, de pensamento e de tradução, podendo ganhar outro sentido em outros momentos da vivência do sujeito: "É fácil, dentro dos limites em que se detêm essas duas iniciativas de apreensão do uso de uma língua, perceber que somente as correlações do significante com o significante fornecem o padrão de qualquer busca de significação" (LACAN, 1998, p. 505).

Para Lacan, não existe um sentido a priori para o significante, como grande parte das instituições sociais pretendem nos fazer crer. O sentido de um significante se faz em ato, no momento em que a letra é dita, escrita e traduzida. Seguindo esse pensamento, traduzir A espera o esquecimento demanda, como primeira regra, compreender que o sentido possível de sua letra se faz a partir do interior de sua estrutura ficcional, jamais de seu exterior ficcional, pois, diz Blanchot (1997, p. 313) em outro momento de escrita, a "linguagem corrente chama um gato de gato, como se o gato vivo e o seu nome [letra/significante] fossem idênticos, como se o fato de nomear não consistisse em reter dele somente a ausência, o que ele não é". A ausência, ou o vazio do abismo, entre significante e significado - que a linguagem corrente procura sublimar para que uma ideia de ordem, por meio da linguagem, possa prevalecer -, é elevada ao primeiro plano na narrativa desse autor. Na verdade, o tradutor, se mantiver uma relação ética com a letra blanchotiana, com a sua diferença, compreenderá que está traduzindo muito mais um nada de escrita, um vazio de discurso, do que uma materialidade de escrita. Daí deriva também outra dificuldade de traduzir Blanchot, pois, nele, não se trata de apresentar e/ou apreender sentidos, mas de problematizar o sentido e, sobretudo, o significante/a letra que se supõe significar ou que esteja dotado/a aparentemente de significação. E, com isso, entre o significante blanchotiano e o seu im-possível significado se introduz uma [ / ] nos moldes descritos por Lacan (1998): 


\section{Original:}

Il commença d'entendre à côté de ce qu'elle disait, et comme en arrière, mais dans une étendue sans profondeur, sans haut ni bas, et pourtant matériellement situable, une autre parole avec laquelle la sienne n'avait presque rien de commun (BLANCHOT, 1962, p. 20).

Tradução:

Ele começou a escutar junto ao que ela dizia, e como que por trás, mas em uma extensão sem profundidade, sem alto nem baixo, e no entanto materialmente situável, uma outra palavra com a qual a sua não tinha quase nada em comum.

Entre a palavra da voz narrativa (ela) e a palavra corrente (ele) se inscreve uma [ / ] (o incomum). Dando continuidade à sua teoria do significante, o psicanalista confere à [ / ] que separa o significante do significado uma importância fundamental, pois é a [ / ] que demarca a impossibilidade de uma significação plena entre significante e significado; e, sobretudo, é a [ / ] que demarca a supremacia do significante em relação ao significado, como o psicanalista deixa bastante claro na estrutura da fórmula de seu algoritmo S/s, no qual se lê: "significante sobre significado, correspondendo o 'sobre' à barra que separa as duas etapas" (LACAN, 1998, p. 500). A [ / ] representa algo que está além, para-além, de uma interrupção da significância, ela representa, na verdade, a falta que subsiste na formação da própria linguagem, um nada formal que vaga sob a cadeia significante da qual nos apropriamos para nos comunicar e, no que nos interessa aqui, traduzir: "nada é do que não nasceu, e tudo o que existe não vive senão na falta a ser" (p. 345). Nessa perspectiva, a [ / ] é visualmente aquilo que fica por (não) dizer, o lapso na fala, o ato falho, a perda na tradução entre-línguas, o gaguejar deleuziano, o Outro barrado (A) e, por fim, o que escapa à intenção do dizer: "[é] no significante, e uma vez que o sujeito articula uma cadeia significante, que ele sente de perto, que ele pode faltar à cadeia do que ele é" (p. 346). Essa falta, por sua vez, é condicionada pela morte, quando a coisa ou o ser se torna nome, letra, palavra: "[é] fato que a letra mata, dizem, enquanto o espírito vivifica" (p. 512).

Para ser comunicável, é essencial que o ser ou a coisa se reduza a um nome, cindindo-se, assim, no duplo raio divergente, como nos assegura Lacan (1998, p. 501): "o da causa em que ela [a coisa] encontrou abrigo em nossa língua e o do nada ao qual abandonou sua veste latina (rem)". Reduzir algo ou uma coisa a um nome, a uma letra, é experienciar a falta/a ausência presente na linguagem, uma vez que a linguagem deve a sua existência à morte. Segundo Blanchot (1997), falar é estar muito próximo 
da morte, da morada da morte, sob o seu abrigo. Com isso, em A espera o esquecimento, a voz narrativa, sendo sobretudo linguagem, diz da espera que é tanto o ato de morrer em vão por esperar algo que jamais chegará pois o chamamento inconsciente da distância tudo impossibilita -, quanto a espera provocada pela morte, a espera enquanto morte-linguagem:

No original:

* Les morts ressuscitaient mourants (BLANCHOT, 1962, p. 43).

Tradução:

* Os mortos ressuscitavam moribundos.

Nessa narrativa, a morte é como a base estrutural de seu discurso ficcional: im-possibilitando o ato de linguagem que se faz da espera e do esquecimento. A morte é o que vivifica (possibilitando a linguagem) matando (impossibilitando a sua significação plena, tornando-a moribunda). E, no processo dessa tradução, o tradutor, caso seja também leitor de Blanchot, ${ }^{4}$ fará as associações necessárias da morte-palavra presente na narrativa com a morte-palavra presente em outros textos do escritor para que a presença da morte experienciada em $A$ espera o esquecimento possa encontrar seus elos de convergência-divergência em outras obras blanchotianas, motivando assim o seu leitor da tradução a seguir um caminho pelo qual ele irá se deparar com a possibilidade de compreensão do significante morte, que ora é a morte mesma, ora é a linguagem, como escreve Blanchot (1997, p. 323) em seu texto "A literatura e o direito à morte", de A parte do fogo:

Para falar, devemos ver a morte, vê-la atrás de nós. Quando falamos, nós nos apoiamos num túmulo, e esse vazio do túmulo é o que faz a verdade da linguagem, mas ao mesmo tempo o vazio é realidade e a morte se faz ser. Existe ser - isto é, uma verdade lógica e expressável - e existe um mundo porque podemos destruir as coisas e suspender a existência. É nisso que podemos dizer que existe ser, porque existe o nada: a morte é a possibilidade do homem, é sua chance, é por ela que nos resta o futuro de um mundo realizado; a morte é a maior esperança dos homens, sua única esperança de serem homens.

${ }_{4}^{4}$ Indico a leitura do meu artigo "O tradutor-leitor de Maurice Blanchot", publicado nos Cadernos de Tradução, da UFSC, no qual apresento a importância de o tradutor de Blanchot ser também o seu leitor. 
Porém, se, por um lado, a morte torna possível a linguagem, auxiliando o homem em seu ato de nomeação do mundo; por outro lado, a morte corrompe a estrutura da linguagem ao inserir nela uma falta incomensurável, um vazio dilacerante que barra toda e qualquer significação plena: "[a] palavra me dá o ser, mas ele me chegará privado de ser. Ela é a ausência desse ser, seu nada, o que resta dele quando perdeu o ser, isto é, o único fato que ele não é" (BLANCHOT, 1997, p. 311). Desse modo, estando a morte presente na letra e a barra separando significante e significado, não há meios para que o ato tradutório se circunscreva somente à captação de sentido da língua de partida e muito menos se estabeleça somente na prática das equivalências linguísticas, pois, como pontua Berman (2007, p. 32), a "fidelidade ao sentido opõe-se - como para o crente e o filósofo - à fidelidade à letra. Sim, a fidelidade ao sentido é obrigatoriamente uma infidelidade à letra”. Logo, ser fiel ao sentido é ser infiel ao caráter ético que se deseja, neste artigo, articular com o ato tradutório. Ao trazer a questão da barra lacaniana para a tradução, posso interpretá-la também, a meu ver, como a barra ética própria à tradução que se deseja ética, como o ato tradutório ético proposto por Berman em A tradução e a letra ou O albergue do longínquo. A [ / ] ética na tradução é, sobretudo, o respeito pela estrangeiridade do outro, quando separa a instância de nossa subjetividade da alteridade do outro, quando impõe a não aclimatação da língua de partida à língua de chegada e quando assume as perdas inevitáveis sempre presentes no ato de se traduzir uma língua estrangeira. A [ / ] ética é a im-possibilidade da tradução plena. Se, em qualquer língua, a relação entre significante e significado é barrada, como nos alerta Lacan, o mesmo e mais radicalmente ocorrerá na tradução entre-línguas, em que significantes e significados são e estão constantemente barrados.

Seguindo esse percurso, fazer da prática da tradução uma prática ética é, também, assumir o luto derivado da [ / ] ética: "[b]em, chegou-se a esse ponto de dramatização em que o trabalho do luto encontra seu equivalente em tradutologia [...]. Eu o resumirei em uma palavra: renunciar ao ideal da tradução perfeita" (RICEEUR, 2011, p. 27). O autor, em Sobre a tradução, incorpora ao trabalho do tradutor o do luto descrito por Freud, principalmente em Luto e melancolia. Neste livro, o psicanalista nos diz que o luto é a reação à perda de uma pessoa amada ou de alguma abstração que possa ser comparável ou que possa estar no lugar de uma pessoa querida que morreu. Em nosso caso, o lugar do morto estimado 
é ocupado pela tradução perfeita, plena e ideal. A perda, dirá ele, será abrandada pelo trabalho do luto:

Então, em que consiste o trabalho realizado pelo luto? Creio que não é forçado descrevê-lo da seguinte maneira: a prova de realidade mostrou que o objeto amado já não existe mais e agora exige que toda a libido seja retirada de suas ligações com esse objeto (FREUD, 2011, p. 49).

No campo da tradução ética, a prova de realidade freudiana se dá quando o tradutor assume a [ / ] que se finca entre as línguas em tradução e abandona deliberadamente a idealidade da tradução "palavra por palavra”. Assumir a não plenitude tradutória é estar pronto para assumir o nada significante que constitui, antes de se tornar palavra e letra, a linguagem que estrutura o nosso inconsciente: "É porque há linguagem que o inconsciente e a língua existem. E, por causa disto, o falante pode se servir da língua para significar o que, do ponto de vista da própria língua, não faz sentido" (FERREIRA, 2002, p. 125).

Em tradução, ater-se ao "sentido" do significante da língua de partida, bem como manter inviolável a estrutura da língua de chegada, é fazer tradução em uma única língua, jamais entre-línguas, pois, ao aniquilar o outro-estrangeiro, o sujeito-tradutor decreta o primado de sua língua e a condenação da língua do outro, instituindo a sua como a língua dentre todas as outras, não havendo, portanto, precisão de uma relação com outra língua já que a sua se basta, "e considera o que se encontra fora dela - o Estrangeiro - como negativo ou, no máximo, bom para ser anexado, adaptado, para aumentar a riqueza desta cultura" (BERMAN, 2007, p. 28). Optando por uma outra via, a via ética da tradução, Blanchot, em seu texto "Traduire" ["Traduzir"], presente em L'amitié [A amizade], reitera que o verdadeiro trabalho do tradutor é aquele que assegura a différence [diferença] do outro-estrangeiro, no que corresponde à fidelidade à sua letra, não no sentido "palavra por palavra", mas no de abrir-se sintática e semanticamente à estranheza provinda da língua de partida, modificando, quando preciso, a sua própria sintaxe para hospedá-la em sua total integridade, embora saibamos que integralidade total em termos de tradução seja impossível, porém, não significa dizer que não possamos desejar buscá-la:

No original:

Il est le maître secret de la différence des langues, non pas pour l'abolir, mais pour l'utiliser, afin d'éveiller, dans la sienne, par les changements violents ou subtils qu'il lui apporte, une présence de ce qu'il y a de différent, originellement, dans l'original (BLANCHOT, 1971, p. 71). 
Tradução:

Ele [tradutor] é o mestre secreto da diferença das línguas, não para aboli-la, mas para utilizá-la, a fim de despertar, na sua, pelas modificações violentas ou sutis que lhe provoca, uma presença do que há de diferente, originalmente, no original.

Em diálogo com Blanchot, Haroldo de Campos, em “Transluciferação mefistofáustica”, texto de 1980 presente no livro Deus e o diabo no Fausto de Goethe, declara: ao "invés de aportuguesar o alemão, germanizo o português, deliberadamente, para o fim de alargar-lhe as virtualidades criativas" (CAMPOS, 2008, 194). E, em 1985, Berman, em sintonia com o pensamento de Blanchot e com o de Campos, dirá, em A tradução e a letra ou O albergue do longínquo:

Como eu estava dizendo: abrir o Estrangeiro ao seu próprio espaço de língua. Abrir é mais que comunicar: é revelar, manifestar. [...] O objetivo ético, poético e filosófico da tradução consiste em manifestar na sua língua esta pura novidade ao preservar sua carga de novidade" (BERMAN, 2007, p. 69).

Neste artigo, a novidade, a estranheza, a trans-criação e a différence foram os princípios éticos que busquei desenvolver, e apresentar, na tradução dos fragmentos escolhidos da narrativa blanchotiana $A$ espera o esquecimento, assim como na tradução dos demais textos aqui citados. Ao traduzir em ato Blanchot, a partir de sua letra e respeitando o seu lugar estrangeiro, demonstrei como a reflexão sobre o outro já se encontra tematizada em sua ficção, possibilitando ao seu tradutor refletir duplamente sobre esse tema: primeiro, sobre o outro enquanto instância im-possível e in-apreensível; e, segundo, sobre o outro enquanto letra estrangeira. Nos dois casos, o caráter ético foi fundamental:

No original:

Il s'agit, bien davantage, d'une identité à partir d'une altérité: la même œuvre dans deux langues étrangères et en raison de leur étrangeté et en rendant, par là, visible ce qui fait que cette œuvre sera toujours autre, mouvement dont il faut précisément tirer la lumière qui éclairera, par transparence, la traduction (BLANCHOT, 1971, p. 72).

Tradução:

Trata-se, muito mais, de uma identidade a partir de uma alteridade: a mesma obra em duas línguas estrangeiras e em razão de sua estrangeiridade tornando, com isso, visível o que faz com que essa obra seja sempre outra, movimento do qual é preciso necessariamente extrair a luz que iluminará, por transparência, a tradução. 


\section{A DES-SUBJETIVAÇÃO DO OUTRO}

"L’autre 'assumé' - c'est autrui." (Emmanuel Levinas. Le temps et l'autre)

Em Blanchot, a alteridade do outro é compreendida em termos de dessubjetivação, ou seja, des-subjetivação, entendendo o prefixo desem seu grau máximo de negação, de ação contrária e de separação. Esse movimento do negativo blanchotiano se manifesta, sobretudo, por meio da palavra, da letra:

- Nisto, afirma esta descontinuidade decisiva de toda relação que está sempre implicada e dissimulada na relação entre o homem e o homem. A palavra diz isto: distância e diferença infinitas, distância que se atesta na própria palavra e a mantém fora de toda contestação, de toda igualdade e de todo comércio (BLANCHOT, 2010a, p. 116).

Em "A palavra plural (palavra de escrita)", tomo I de $A$ conversa infinita, Blanchot (2010a, p. 114, grifo meu) conduz o pensamento sobre o outro a partir de uma estrutura textual dialógica entre dois seres, que se transformará rapidamente em uma conversa infinita, dado o caráter de in-apreensibilidade do outro por meio da palavra, isto é, por meio da materialidade do significante: "A palavra afirma o abismo existente entre 'eu' e 'outrem' e ela ultrapassa o intransponível, mas sem aboli-lo nem diminui-lo". E conclui: "[a]lém do mais, sem esta infinita distância, sem esta separação do abismo, não haveria palavra, de maneira que é correto dizer que toda verdadeira palavra lembra-se desta separação pela qual ela fala" (BLANCHOT, 2010a, p. 114). Em toda palavra, há a [ / ], não nos esqueçamos disso, que tanto impossibilita a significação plena, quanto permite a via ética para a tradução, ao tornar abissal a relação entre mim e o outro, aquele que se encontra des-subjetivado, tamanha a complexidade de sua alteridade: “[o]utrem, se é mais elevado, é também menor do que eu, mas sempre outro: o Distante, o Estrangeiro. Minha relação com ele é uma relação de impossibilidade, escapando ao poder" (p. 114).

Publicada originalmente em 1969, A conversa infinita é, a bem da verdade, uma retomada de conversas infinitas já iniciadas em textos ficcionais de Blanchot, como, por exemplo, em A espera o esquecimento, de 1962. Entretanto, para o tradutor de $A$ espera o esquecimento, a questão do outro ganha uma complexidade maior, pois o outro, agora, além de ser o outro, é o outro-estrangeiro - duas camadas de im-possibilidade e 
de distanciamento intervêm em seu processo de tradução, juntamente com a problematização da palavra, que mantém o abismo "entre 'eu' e 'outrem”. A tradução dessa narrativa se faz exatamente nessa tensão da im-possibilidade do ato de traduzir, a começar pela tradução de seu título. Como destaca Jacques Derrida, em “Titre à préciser" [“Título a precisar”], do livro Parages [Paragens], os títulos das narrativas de Blanchot não são apenas títulos, ou melhor, não são apenas nomes que intitulam uma obra, mas textos, eles próprios capazes de entrar em acordo ou não com o material de escrita apresentado no interior da obra que intitulam: "[o] título então, eis ele pronto a fazer a lei desde a reserva enigmática, na elipse em que ele se mantém, perto da borda, sobre a borda, nem no poema nem fora dele, em seu nome próprio suspenso" (DERRIDA, 2003, 216). ${ }^{5}$ Em se tratando do título de $A$ espera o esquecimento, Blanchot, ao abrir mão tanto da [ , ] como sinal gráfico de pontuação (que conferiria uma certa parada na leitura de seu título, materializando, assim, a espera para logo depois vir o esquecimento, como se houvesse uma continuidade entre os substantivos em questão), quanto da conjunção aditiva [ e ] (que atribuiria ao título uma ideia de soma, supondo a possibilidade de um resultado, como se um terceiro elemento resultasse da soma da espera e do esquecimento), opta por deixar em aberto a relação entre a espera e o esquecimento, relação esta que permanecerá presente-ausente, pois o outro, que nessa narrativa toma também a forma de um ela e de uma ideia de obra literária, do feminino enquanto obra literária, torna-se continuamente aquele que se distancia, do qual se esquece, embora seja sempre esperado em vão, irredutivelmente esperado como promessa:
No original:
La pensée de l'attente: la pensée qui est l'attente de ce qui ne se laisse pas penser, pensée que porte l'attente et ajournée en cette attente (BLANCHOT, 1962, p. 77).
Tradução:
O pensamento da espera: o pensamento que é a espera do que não se deixa pensar, pensamento que carrega a espera e adiado nessa espera.

Elipsando a [ , ] e o [ e ], Blanchot introduz a [ / ], que, além de im-possibilitar uma significação plena da letra e da tradução de sua letra,

\footnotetext{
5 "Le titre alors, le voici prêt à faire la loi depuis la réserve énigmatique, dans l'ellipse où il se tient, près du bord, sur le bord, ni dans le poème ni hors de lui, en son nom propre suspendu."
} 
uma vez que algo sempre restará in-alcançável para o tradutor, deixa vir à tona o vazio, o oco e o silêncio do significante:

\begin{abstract}
No original:
Ils cherchaient l'un et l'autre la pauvreté dans le langage. Sur ce point, ils s'accordaient. Toujours, pour elle, il y avait trop de mots et un mot de trop, de plus des mots trop riches et qui parlaient avec excès. Bien qu'elle fût apparemment peu savante, elle semblait toujours préférer les mots abstraits, qui n'évoquaient rien. Est-ce qu'elle n'essayait pas, et lui avec elle, de se former au sein de cette histoire un abri pour se protéger de quelque chose que l'histoire aussi contribuait à attirer? Il y avait des moments où il le croyait et des phrases qui le lui faisaient croire (BLANCHOT, 1962, p. 16).
\end{abstract}

Tradução:

Um e outro procuravam a pobreza na linguagem. Sobre esse ponto, eles concordavam. Sempre, para ela, havia palavras demais e uma palavra a mais, além disso palavras muito ricas e que falavam em excesso. Embora ela fosse aparentemente pouco erudita, ela parecia sempre preferir as palavras abstratas, que não evocavam nada. Será que ela não tentava, e ele com ela, formar no seio dessa história um abrigo para se proteger de alguma coisa que a história também contribuía para atrair? Havia momentos em que ele acreditava nisso e frases que o faziam acreditar nisso.

Respeitar a letra estrangeira de Blanchot - que, como nos lembra Jacques Derrida, é estrangeira inclusive no próprio francês, quando o escritor res-significa, re-estrutura e re-distribui os componentes da língua francesa em novas categorias significantes antes impensáveis para a sua língua - é manter, no caso de $A$ espera o esquecimento, a différence que se deixa entrever nos espaços vazios das palavras que estruturam o infinito diálogo entre o ele-sujeito e o ela-outro. Em muitos de seus longos sintagmas, não há sinais gráficos de pontuação, apenas palavras, como se uma verborragia se fizesse necessária, pois o esquecimento está a todo instante presente-ausente e se querendo estabelecer por completo na narrativa, a ponto de olvidar tudo e todos, inclusive leitor e tradutor. Por essa razão, é necessário que ele e ela, ambos sem nomes, produzam palavras e esperem delas algum significado, por mais que o resultado dessa espera seja quase sempre o seu contrário, a incompreensão, que, por sua vez, nos incita a desejar compreender e a permanecer em sua narrativa, tanto pela via da leitura quanto pela via da tradução da letra (do outro e do outro-estrangeiro):

No original:

* Exprimer cela seulement qui ne peut l'être. Le laisser inexprimé (BLANCHOT, 1962, p. 27). 
Tradução:

* Exprimir somente isso que não pode sê-lo. Deixá-lo inexpressível.

Nesse fragmento, observamos um dos principais desvios constitutivos da im-possibilidade de sua tradução, refiro-me ao pronome cela [isso]. $\mathrm{Na}$ composição narrativa de $A$ espera o esquecimento, o pronome demonstrativo cela se demora sem referente, esvaziado de qualquer referente e de qualquer referência, pois esse pronome não se reporta a algo dito anteriormente pelas vozes narrativas nem a algo que será revelado posteriormente por elas, não sendo de fato um pronome demonstrativo ipsis litteris. E o que isso significa? Significa que o tradutor deve estar atento aos jogos sem objetivo das estruturas sintáticas e semânticas blanchotianas, para não recorrer à prática da racionalização, ao procurar dar significação ao outro-estrangeiro, deformando-o e invadindo o seu espaço da letra:

A racionalização diz respeito em primeiro lugar às estruturas sintáticas do original, bem como a este elemento delicado do texto em prosa que é a pontuação. A racionalização re-compõe as frases e sequências de frases de maneira a arrumá-las conforme uma certa ideia da ordem de um discurso. [...] A racionalização conduz violentamente o original de sua arborescência à linearidade (BERMAN, 2007, pp. 48-49).

O cela [isso] blanchotiano talvez se reporte a algo ainda inexistente, que se constitui enquanto espera, a espera por algo ainda por vir não vindo, mas que ambos continuam a esperar, por isso a sua não significância no instante em que é proferido por uma das duas vozes narrativas. No entanto, o significante cela, embora não se sobrecarregue de um significado prévio, já dado, faz um movimento de antecipação de um significado por vir, ainda que esse significado reste inacessível às vozes narrativas, ao leitor e ao tradutor:

No original:

L'oubli est rapport avec ce qui s'oublie, rapport qui, rendant secret cela avec quoi il y a rapport, détient le pouvoir et le sens du secret (BLANCHOT, 1962, p. 67).

Tradução:

O esquecimento é relação com o que se esquece, relação que, tornando secreto isso com o que há relação, detém o poder e o sentido do segredo.

Em sua antecipação do sentido ainda por vir, o cela [isso] blanchotiano faz com que o escritor dialogue mais uma vez com Lacan (1998, p. 505): 
"[p]ois o significante, por sua natureza, sempre se antecipa ao sentido, desdobrando como que adiante dele sua dimensão". Com sua estrutura textual dialógica que não pretende chegar a um objetivo, a uma resposta e a uma compreensão de algo específico, A espera o esquecimento opera um movimento de escrita cujo fim despretensioso será a obra, a obra $A$ espera o esquecimento, da qual dispomos para ler e traduzir. Quando o tradutor se depara com uma obra que não se quer obra no sentido tradicional do termo, ou seja, obra que não deseja passar uma mensagem específica ou mesmo qualquer mensagem, ele é obrigado a se despir do que aprendeu como tradução, no sentido genérico do termo, em favor da tradução dessa obra não obra.

E é preciso ressaltar: quando se traduz Blanchot, não apenas se traduz, mas se traduz Blanchot. A diferença é sutil, mas reveladora. O autor comporta uma différence inalienável que se modifica a cada texto de sua autoria; cada narrativa é inaugural, é específica, não podendo ser objeto de comparação ou de exemplificação para as demais obras do escritor, pois o seu trabalho de clivagem da letra ganha contornos diversos em cada obra sua, tanto aquelas com um olhar mais crítico, quanto as claramente ficcionais.

Em sua différence, esse autor demanda de seu tradutor um trabalho ético, no que compete ao espaço do outro enquanto différence, estrangeiridade que precisa ser mantida, caso o tradutor deseje entregar ao seu leitor a letra estrangeira de Blanchot, ainda que isso leve a desconstruir e a reconstruir a própria sintaxe dele:

No original:

* "Porquoi pensez-vous cela?" - "Je le pense, je le penserai toujours. C'est une pensée à laquelle on ne peut mettre fin". Il frissonna en entendant cette sorte de condamnation (BLANCHOT, 1962, p. 47).

Tradução:

* "Por que você pensa isso?” - “Eu o penso, eu o pensarei sempre. É um pensamento ao qual não se pode pôr fim.” Ele tremeu escutando essa espécie de condenação.

Na tradução desse fragmento, para fazer do português uma morada para o francês blanchotiano, respeitando-lhe sobretudo a sua estrangeiridade, optou-se por dois movimentos sintáticos possibilitados pela estrutura da língua portuguesa, embora esse recurso seja muitas vezes estranho ao leitor brasileiro: a repetição do pronome pessoal do caso reto [ eu ] para acompanhar a intensidade da resposta do ela-outro e 
a posição do pronome pessoal do caso oblíquo [ o ]. Para que a novidade e a différence da letra de Blanchot pudessem estar presentes nessa tradução foi necessário abrir bermanianamente a língua portuguesa: "a tradução 'literal' (vinculada à letra) é aquela que cumpre o objetivo ético e, mais profundamente ainda, esse momento da obra que é sua Verjüngung [rejuvenescimento]" (BERMAN, 2007, p. 71). O ela-outro, enquanto obra por vir, é aquele que inspira o ele-sujeito que se deseja escritor:

No original:

Ici, et sur cette phrase qui lui était peut-être aussi destinée, il fut contraint de s'arrêter. C'est presque en l'écoutant parler qu'il avait rédigé ces notes (BLANCHOT, 1962, p. 7).

Tradução:

Aqui, e nesta frase que lhe era talvez também destinada, ele foi obrigado a parar. É quase em a escutando falar que ele tinha redigido essas anotações.

Ao fim da narrativa, o diálogo entre ele e ela resta em aberto, abandonando qualquer significação para ser obra, obra significante, $A$ espera o esquecimento, que não pertence nem a ele e que nem se origina apenas dela, mas de ambos enquanto construções significantes, enquanto materializações da letra blanchotiana:

No original:

"J'ai peur, je me souviens de la peur." - "Cela ne fait rien, ayez confiance en votre peur." Et ils continuèrent à avancer (BLANCHOT, 1962, p. 119).

Tradução:

“Tenho medo, eu me lembro do medo." - “Isso não importa, tenha confiança em seu medo.” E eles continuaram avançando.

Quando se chega à última frase de $A$ espera o esquecimento, o tradutor, que optou por um trabalho de tradução ética, dar-se-á conta de que traduziu a partir do esquecimento e o que esperava, a obra traduzida, permaneceu ainda por vir, uma obra por vir vindo, estando, embora ainda esteja por vir, cujo sentido permanece sendo ultrapassado continuamente pelo significante, pela letra:

No original:

* C'est comme s'ils avaient toujours à chercher le chemin pour parvenir où ils sont déjà (BLANCHOT, 1962, p. 92). 
Tradução:

* É como se eles tivessem sempre a procurar o caminho para chegar aonde eles já estão.

Com Blanchot, aprendemos que o trabalho do tradutor se confunde, por vezes, com essa espera, espera de uma obra traduzida por vir que acompanhe de perto, embora ao longe, o outro-estrangeiro, na qual ambos, esperando, mantenham a distância necessária para se fazer a obra... traduzida.

\section{REFERÊNCIAS}

BENJAMIN, Walter. A tarefa do tradutor. In: Escritos sobre mito e linguagem. Trad. Susana Kampff Lages e Ernani Chaves. São Paulo: Duas Cidades, Editora 34, 2013, pp. 101-119.

BERMAN, Antoine. A tradução e a letra ou o albergue do longínquo. Trad. Marie-Hélène Catherine Torres, Mauri Furlan, Andréia Guerini. Rio de Janeiro: 7Letras/PGET, 2007.

BLANCHOT, Maurice. L'attente l'oubli. Paris: Gallimard, 1962.

BLANCHOT, Maurice. Traduire. In: L'amitié. Paris: Gallimard, 1971, pp. 69-73.

BLANCHOT, Maurice. A parte do fogo. Trad. Ana Maria Scherer. Rio de Janeiro: Rocco, 1997.

BLANCHOT, Maurice. A conversa infinita. Tomo I. Trad. Aurélio Guerra Neto. São Paulo: Escuta, 2010a.

BLANCHOT, Maurice. A conversa infinita. Tomo III. Trad. João Moura Jr. São Paulo: Escuta, 2010b.

CAMPOS, Haroldo de. Deus e o diabo no Fausto de Goethe: marginália fáustica: (leitura do poema, acompanhada da transcriação em português das duas cenas finais da segunda parte). São Paulo: Perspectiva, 2008.

DERRIDA, Jacques. Parages. Paris: Galilée, 2003.

FERREIRA, Nadiá Paulo. Jacques Lacan: apropriação e subversão da linguística. Ágora, V. 5, n. 1, 2002, pp. 113-132.

FREUD, Sigmund. Luto e melancolia. Trad. Marilene Carone. São Paulo: Cosac Naify, 2011. 
FREUD, Sigmund. Totem e tabu, contribuição à história do movimento psicanalítico e outros textos (1912-1914). Obras completas, v. 11. Trad. Paulo César de Souza. São Paulo: Companhia das Letras, 2012.

FREUD, Sigmund. Três ensaios sobre a teoria da sexualidade, análise fragmentária de uma histeria ("O caso Dora”) e outros textos (1901-1905). Obras completas, v. 6. Trad. Paulo César de Souza. São Paulo: Companhia das Letras, 2016.

LACAN, Jacques. A instância da letra no inconsciente ou a razão desde Freud. In: Escritos. Trad. Vera Ribeiro. Rio de Janeiro: Zahar, 1998, pp. 496-533.

LACAN, Jacques. Prefácio à edição inglesa do Seminário 11. In: Outros escritos. Trad. Vera Ribeiro; versão final Angelina Harari e Marcus André; preparação de texto André Telles. Rio de Janeiro: Zahar, 2003, pp. 567-569.

LACAN, Jacques. Seminário, livro 7: a ética da psicanálise (1959-1960). Trad. Antônio Quinet. Rio de Janeiro: Zahar, 2008.

LEVINAS, Emmanuel. Le temps et l'autre. Paris: Fata Morgana, 2011.

PIMENTEL, Davi Andrade. O tradutor-leitor de Maurice Blanchot. Cadernos de Tradução, v. 37, n. 3, set-dez 2017, pp. 53-70.

RICOEUR, Paul. Sobre a tradução. Trad. Patrícia Lavelle. Belo Horizonte: Editora UFMG, 2012.

Recebido: 9/5/2021

Aceito: 22/6/2021

Publicado: 22/12/2021 